\title{
Nitric oxide attenuates cardiomyocytic apoptosis via diminished mitochondrial complex I up-regulation from cardiac ischemia-reperfusion injury under cardiopulmonary bypass
}

\author{
Chi-Hsiao Yeh, MD \\ Yu-Min Lin \\ Yi-Cheng Wu, MD \\ Yao-Chang Wang, MD \\ Pyng Jing Lin, MD
}

\footnotetext{
From the Division of Thoracic and Cardiovascular Surgery, Chang Gung Memorial Hospital, Taoyuan, Taiwan.

Part of this research was supported by grant NSC 87-2314-B-182-025 from the National Science Council of the Republic of China.

Received for publication May 23, 2003; revisions received Oct 20,2003; accepted for publication Nov 4, 2003.

Address for reprints: Dr Chi-Hsiao Yeh, MD, Division of Thoracic and Cardiovascular Surgery, Chang Gung Memorial Hospital, 5 Fu-Hsing Street, Kweishan, Taoyuan, Taiwan 333 (E-mail: yehccl@ cgmh.org.tw)

J Thorac Cardiovasc Surg 2004;128:180-8 $0022-5223 / \$ 30.00$

Copyright ( $\odot 2003$ by The American Association for Thoracic Surgery

doi:10.1016/j.jtcvs.2003.11.056
}

\begin{abstract}
Objective: This study tested the hypothesis that cardioplegic solution supplemented with a nitric oxide donor agent attenuates postischemic cardiomyocytic apoptosis by reduction of mitochondrial complex I up-regulation during global cardiac arrest under cardiopulmonary bypass.
\end{abstract}

Methods: Twenty-four anesthetized dogs supported by total vented bypass were divided evenly into 4 groups $(\mathrm{n}=6)$ and subjected to 60 minutes of hypothermic ischemia followed by $4^{\circ} \mathrm{C}$ multidose crystalloid cardioplegic solution infusion. Hearts received either standard crystalloid cardioplegic solution (control), crystalloid cardioplegic solution supplemented with $2 \mathrm{mmol} / \mathrm{L}$ L-arginine (L-Arg group), crystalloid cardioplegic solution supplemented with $400 \mu \mathrm{mol} / \mathrm{L} \mathrm{N}^{\mathrm{G}}$-monomethylL-arginine (L-NMMA group), or crystalloid cardioplegic solution supplemented with $100 \mu \mathrm{mol} / \mathrm{L}$ of NO donor compound (3-morpholinosydnonimine; SIN-1 group). After 60 minutes of cardioplegic arrest, the heart was reperfused for a total of 240 minutes after discontinuation of bypass. The occurrence of cardiomyocytic apoptosis was assessed by terminal deoxynucleotidyl transferase-mediated dUTP-biotin nick end labeling and Western blot analysis of caspase-3.

Results: The occurrence of cardiomyocytic apoptosis was significantly reduced in SIN-1 and L-Arg groups compared with the control group. Mitochondrial complex I mRNA was up-regulated in the control group, and its expression was significantly higher in the L-NMMA group but significantly reduced in the SIN-1 and L-Arg groups. Western blot analysis of Bcl-2 and cytochrome $c$, an index of mitochondrial damage in postischemic myocardium, revealed a similar pattern.

Conclusion: Nitric oxide-supplemented crystalloid cardioplegic solution diminished postischemic cardiomyocytic apoptosis after global cardiac arrest under cardiopulmonary bypass, possibly via prevention of mitochondrial complex I up-regulation.

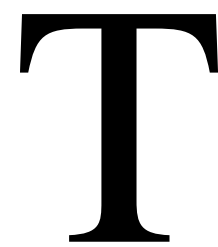
he decreased production of endothelium-derived nitric oxide (NO) has been found to increase myocardial ischemia and reperfusion damage during global cardiac arrest under cardiopulmonary bypass (CPB).$^{1-3}$ The physiologic functions of NO include vasodilation, inhibition of platelet aggregation and neutrophil adhesion, and biradical quenching of superoxide anions. ${ }^{4}$ The attenuation of NO release caused by endothelial damage after reperfusion exacerbates the extent of postischemic cardiomyocytic injury and may be a critical mechanism in the occurrence of cardiomyocytic apoptosis after global cardiac arrest under CPB. 
In the development of cardioplegic solutions for use as cardioprotective strategies, attention has been primarily focused on protecting cardiomyocytes from necrosis and contractile dysfunction. However, recent studies have demonstrated that cardiomyocytic apoptosis after global cardiac arrest under CPB has an important influence on postoperative cardiac function. ${ }^{5}$ A recent study from our laboratory ${ }^{6}$ showed that neither intermittent cold crystalloid nor intermittent cold blood cardioplegic solution could protect cardiomyocytes from apoptosis after global cardiac arrest under CPB. Compared with infusion of continuous tepid blood cardioplegic solution, the coronary endothelial damage was also evident in these 2 cardioprotective methods. However, the protective effect of continuous blood cardioplegic infusion on attenuation of cardiomyocytic apoptosis may come from preservation of the endothelium, which provides NO to the underlying cardiomyocytes. Another study from our laboratory ${ }^{7}$ revealed that continuous tepid warm blood cardioplegic solution could decrease the up-regulation of mitochondrial NADH:ubiquinone oxidoreductase (complex I) mRNA and reduce mitochondrial free radical production. However, the possible role of mitochondria and mitochondrial complex I in NO-regulated protective effect on the occurrence of cardiomyocytic apoptosis during global cardiac arrest under CPB has never been explored.

Cardioplegic solutions could be an ideal vehicle for the introduction of agents that target the perpetrators of endothelial injury during global cardiac arrest under CPB. Replacement of lost (secondary to endothelial damage) endogenous NO with exogenous NO donor or supplementation with the precursor of NO (L-arginine) may prevent cardiomyocytic apoptosis and pathologic sequelae. This study was designed to determine whether (1) the inhibition of endogenous NO production by cardioplegia or NO synthase inhibitor ( $\mathrm{N}^{\mathrm{G}}$-monomethyl-L-arginine, L-NMMA) aggravates cardiomyocytic apoptosis; (2) the NO donor compound (3-morpholinosydnonimine, SIN-1) or NO precursor used in crystalloid cardioplegic solution attenuates postischemic cardiomyocytic apoptosis in dogs subjected to global cardiac arrest under CPB; and (3) NO-regulated protection was achieved via prevention of mitochondrial complex I upregulation and reduction of mitochondrial damage.

\section{Methods}

\section{Animal Model of Global Cardiac Ischemia Using Cardiopulmonary Bypass}

The experimental model was established as previously described. ${ }^{6}$ Briefly, healthy mongrel dogs $(25-30 \mathrm{~kg})$ of either sex were premedicated with ketamine (10 mg/kg intramuscularly), anesthetized with sodium pentobarbital $(30 \mathrm{mg} / \mathrm{kg}$ intravenously), and then given intermittent boluses of pentobarbital $(5 \mathrm{mg} / \mathrm{kg})$ and diazepam $(5 \mathrm{mg})$ as needed during the experiment. Each dog was intubated and ventilated using a respirator. The left femoral artery and vein were catheterized for hemodynamic data collection and fluid administration, respectively. These physiological parameters, including heart rate, blood pressure, and maximal slope of systolic pressure increment $(\mathrm{dP} / \mathrm{dT})$, were analyzed using a computer equipped with an analog/digital converter (DASA 4600, Gould, Inc, Valley View, Ohio) and software (BioCybernatics 1.0, Taipei, Taiwan). The rectal temperature was monitored. After right thoracotomy, the pericardium was opened and tented to cradle the heart. The aorta was cannulated for aortic perfusion after heparinization $(250 \mathrm{U} / \mathrm{kg})$, and the upper and lower caval veins were transatrially cannulated for venous return. The left ventricle was vented directly by a catheter inserted though the left atrial appendage. Cardiopulmonary bypass was instituted with a membranous oxygenator (Maxima Plus oxygenation system, Medtronic, Inc Cardiopulmonary Division, Anaheim, Calif) with a flow rate at 50 $\mathrm{mL} / \mathrm{kg} / \mathrm{min}$. After stabilization, the ascending aorta was crossclamped. A double-lumen aortic root cannula (DPL, Inc, Grand Rapids, Mich) was inserted for antegrade delivery of cardioplegic solution and simultaneous measurement of infusion pressure. All infusions of cardioplegic solution were administered around 40 to $60 \mathrm{~mm} \mathrm{Hg}$ pressure.

The body temperature during cardiopulmonary bypass was kept around $28^{\circ} \mathrm{C}$. The ascending aorta was crossclamped for $60 \mathrm{~min}-$ utes, and intermittent crystalloid cold $\left(4^{\circ} \mathrm{C}\right)$ cardioplegic solutions $(10 \mathrm{~mL} / \mathrm{kg})$ were delivered to induce cardiac arrest. The cardioplegic solution was reinfused $(4 \mathrm{~mL} / \mathrm{kg})$ at 20 -minute intervals during global ischemia. All aspects of this investigation conformed with the Guide for the Care and Use of Laboratory Animals published by the US National Institutes of Health (National Institutes of Health Publication No. 85-23, revised in 1996).

\section{Experimental Protocol}

Dogs were randomly divided into 4 groups of 6 dogs as follows: (1) the control group received an infusion of cold crystalloid cardioplegic solution (Plegisol, Abbott Laboratories, Chicago, Ill) with the following electrolyte composition (in milliequivalents per liter): calcium, 2.4; magnesium, 32; potassium, 16; sodium 120; and chloride 160 ; (2) the L-arginine (L-Arg) group received an infusion of cold crystalloid cardioplegic solution supplemented with $2 \mathrm{mmol} / \mathrm{L}$ L-arginine; (3) the L-NMMA group was infused with crystalloid cardioplegic solution supplemented with 400 $\mu \mathrm{mol} / \mathrm{L}$ L-NMMA; and (4) the SIN-1 group was infused with crystalloid cardioplegic solution supplemented with $100 \mu \mathrm{mol} / \mathrm{L}$ SIN-1.

After 60 minutes of aortic crossclamping, the infusion of cardioplegic solution was stopped, the crossclamp was removed, and systemic rewarming to $37^{\circ} \mathrm{C}$ was achieved. CPB was then discontinued, and the mean arterial pressure was maintained at approximately $50 \mathrm{~mm} \mathrm{Hg}$. After 4-hour reperfusion in the working state, portions of the hearts were fresh harvested and stored in liquid nitrogen until further use, while the remaining portions were perfusion fixed with $4 \%$ paraformaldehyde before excision. Blood samples were obtained before surgery and serially after surgery for measurement of cardiac troponin I (cTnI) and total protein. The blood samples were taken at baseline (before anesthetic induction), upon establishment of $\mathrm{CPB}$, after aortic crossclamp release (5 minutes), and 4 hours after reperfusion. Blood was withdrawn from the femoral vein catheter and collected into vacuum tubes. Platelet-poor plasma was prepared by centrifugation at $2000 \mathrm{~g}$ for 
15 minutes and stored in polypropylene tubes at $-70^{\circ} \mathrm{C}$ until further use.

\section{Plasma cTnI Analysis}

Arterial blood samples $(2 \mathrm{~mL})$ were centrifuged at $2000 \mathrm{~g}$ at $4^{\circ} \mathrm{C}$ for 20 minutes, and the plasma was decanted for biochemical analysis. Plasma total protein concentration was assayed using the biuret method. ${ }^{8}$ cTnI was measured on an Axsym system (Abbott Laboratories) and expressed as nanograms per milliliter serum. All assays were measured without knowledge of each dog's experimental group. The detected concentrations were normalized according to dilution factor using plasma total protein as the reference and expressed as an increase (fold) of cTnI above baseline values.

\section{In Vitro Apoptosis Studies}

Terminal deoxynucleotidyl transferase-mediated dUTP-biotin nick end labeling (TUNEL) was performed as described previously. ${ }^{6}$ Paraffin sections were affixed to slides. After deparaffinization, the sections were incubated in $250 \mu \mathrm{L}$ of proteinase $\mathrm{K}$ for 30 minutes at $37^{\circ} \mathrm{C}$ and immersed in terminal deoxynucleotidyl transferase (TdT) buffer. TdT $(2.5 \mu \mathrm{L})$, biotin-dUTP $(2.5 \mu \mathrm{L})$, and TdT buffer (45 $\mu \mathrm{L}$ ) were added to cover the sections, which were incubated in a moist chamber at $37^{\circ} \mathrm{C}$ for 60 minutes. The reaction was terminated by transferring the slides to a buffer containing sodium chloride $(300 \mathrm{mmol} / \mathrm{L})$ and sodium citrate $(30 \mathrm{mmol} / \mathrm{L})$ for 15 minutes at room temperature; the sections were then covered with avidin-fluorescein isothiocyanate solution and stained with propidium iodide for 15 to 20 minutes at $4^{\circ} \mathrm{C}$. After mounting, the specimens were examined by light microscopy, and labeled nuclei were easily identified from the unstained background. Four sections of the reperfused hearts in each animal were examined to determine the percentage of apoptotic nuclei. To quantify apoptosis, 500 nuclei were identified in 10 randomly selected $400 \times$ high-power fields (HPF) per section. Apoptotic cell counts were expressed as a percentage of the total number of nuclei counted. The evidence of apoptosis was intensified with the Western analyses of caspase- 3 and poly-(ADP-ribose) polymerase (PARP) protein (the former was the final executor of apoptosis and the latter was the substrate of caspase-3).

\section{Reverse Transcription Polymerase Chain Reaction}

For reverse transcription polymerase chain reaction (RT-PCR), RNA was extracted from the cardiac specimens using the singlestep method ${ }^{9}$ and the concentration was determined by spectrophotometry. RT was done using $2 \mu \mathrm{L} \mathrm{RNA}$ in a reaction containing $50 \mathrm{mmol} / \mathrm{L}$ Tris (pH 8.3), $75 \mathrm{mmol} / \mathrm{L} \mathrm{KCl}, 3 \mathrm{mmol} / \mathrm{L} \mathrm{MgCl}_{2}$, $1 \mathrm{mmol} / \mathrm{L}$ each of deoxynucleoside triphosphate, $0.25 \mu \mathrm{g}$ each of oligo-deoxythymidine and random hexamer, $20 \mathrm{U}$ human placental ribonuclease inhibitor (RNasin, Promega Biochemicals, Madison, Wis), and 400 U RT (Superscript II, Life Technologies, Rockville, $\mathrm{Md}$ ). The reaction was incubated at $42^{\circ} \mathrm{C}$ for 90 minutes and then inactivated at $90^{\circ} \mathrm{C}$ for 5 minutes.

PCR reactions for NADH:ubiquinone oxidoreductase and glyceraldehyde phosphate dehydrogenase (GAPDH) were done in a $25-\mu \mathrm{L}$ reaction consisting of $1 \mu \mathrm{L}$ cDNA, $10 \times$ PCR reaction buffer (Gibco BRL, Grand Island, NY), $2.5 \mathrm{mmol} / \mathrm{L}$ each of deoxynucleoside triphosphate, $1.125 \mathrm{mmol} / \mathrm{L} \mathrm{MgCl}_{2}$, and 1 $\mathrm{mmol} / \mathrm{L}$ primers, and $0.625 \mathrm{U}$ Taq polymerase with equal amounts of Taq antibody and $4 \times$ Taq antibody buffer (Clontech Laboratories, Inc, Palo Alto, Calif). Reactions were run at $94^{\circ} \mathrm{C}$ for 45 seconds, $60^{\circ} \mathrm{C}$ for 45 seconds, and $72^{\circ} \mathrm{C}$ for 1 minute 30 seconds for 30 cycles, followed by 5 minutes at $72^{\circ} \mathrm{C}$. Two NADH: ubiquinone oxidoreductase gene-specific sense and antisense primers ( 29 and 22 mer, respectively) were designed to hybridize to the detected fragment. NADH:ubiquinone oxidoreductase primers were designed as 5'TGTTCATAATCAGGAAGGATACCTAGTTC 3' (sense) and 5'GCATATTGAGCCCGGTATAGA 3' with a 200 -bp predicted product. ${ }^{7}$ DNA contamination was excluded by PCR of the same samples without previous RT. Identified signal intensities of specific PCR product bands were normalized with that of the GAPDH PCR product to correct for differences in manipulation and expressed as an increase (fold) of mRNA expression above baseline values.

\section{Western Blot Studies}

Tissue levels of caspase-3 protein, PARP protein, Bcl-2, and cytochrome $c$ were determined by Western blot analyses. Because the relative abundance of cell survival regulating factors encoded by the Bcl-2 gene family can strongly affect the decision to undergo apoptosis in response to an external signal, ${ }^{10}$ Western blot analyses were performed for $\mathrm{Bcl}-2$ and cytochrome $c$ proteins. Antiapoptotic Bcl-2 proteins have been identified in the myocardium, and evidence suggests that several of these proteins are regulated following ischemic stress. ${ }^{1-13}$ The release of $\mathrm{Bcl}-2$ during ischemia-reperfusion injury from the outer membrane of mitochondria has been proven to prevent apoptosis by blocking the release of cytochrome $c$ from the mitochondria. ${ }^{14}$ Ten percent (weight/volume) tissue homogenate was prepared in the lysis buffer and centrifuged at $4^{\circ} \mathrm{C}$ and $14,000 \mathrm{~g}$ for 10 minutes. The supernatant was separated on a $12.5 \%$ polyacrylamide denaturing gel and then electroblotted onto Hybond-C nitrocellulose membranes (Amersham Life Science, Little Chalfont, UK). Membranes were blocked by the addition of $3 \%$ bovine serum albumin at $4{ }^{\circ} \mathrm{C}$ overnight before being probed with a polyclonal anti-caspase-3, anti PARP antibodies (PharMingen, San Diego, Calif), a monoclonal anti-Bcl-2, and anti cytochrome $c$ antibodies (PharMingen) at 1:1000 dilution at room temperature for 2 hours. Primary antibody binding was revealed using an anti-rabbit peroxidase conjugate (Dako, Inc, Glostrup, Denmark). Positive controls for Bcl-2, caspase-3, and PARP (NeoMarkers, Fremont, Calif) were used for identification of the corresponding proteins. The membranes were incubated for 1 minute with ECL detection solution, and the levels were determined using an ECL detection kit (Amersham Pharmacia Biotech, Piscataway, NJ). The immunoreactive bands were quantified by digital densitometric imaging (Kodak 1D image analysis software, Kodak).

\section{Data Analysis}

Data are expressed as mean \pm standard error of the mean. Data were entered into Excel (Microsoft Corporation, Redmond, Wash) and analyzed by the Statistical Package for the Social Science (SPSS Inc, Chicago, Ill) version 8.0. One-way analysis of variance followed by Tukey multiple comparison procedure was used to compare differences among groups. 
TABLE 1. Hemodynamic changes compared with baseline $(\%)$ of various groups immediately after release of the aortic clamp, off cardiopulmonary bypass, and 4 hours after reperfusion

\begin{tabular}{|c|c|c|c|c|c|c|c|c|c|}
\hline \multirow[b]{2}{*}{ Group } & \multicolumn{3}{|c|}{ Mean pressure } & \multicolumn{3}{|c|}{ Heart rate } & \multicolumn{3}{|c|}{$\mathrm{dP} / \mathrm{dT}$} \\
\hline & $\begin{array}{c}\text { Crossclamp } \\
\text { off }\end{array}$ & Off CPB & Reperfusion & $\begin{array}{c}\text { Crossclamp } \\
\text { off }\end{array}$ & Off CPB & Reperfusion & $\begin{array}{c}\text { Crossclamp } \\
\text { off }\end{array}$ & Off CPB & Reperfusion \\
\hline Control & $94 \pm 18$ & $102 \pm 11$ & $95 \pm 13$ & $92 \pm 17$ & $94 \pm 12$ & $94 \pm 17$ & $92 \pm 4$ & $92 \pm 3$ & $96 \pm 1$ \\
\hline L-Arg & $92 \pm 10$ & $107 \pm 7$ & $112 \pm 16$ & $96 \pm 8$ & $91 \pm 18$ & $114 \pm 23$ & $95 \pm 19$ & $87 \pm 19$ & $107 \pm 9$ \\
\hline L-NMMA & $86 \pm 11^{*} \dagger$ & $84 \pm 6^{*} \dagger$ & $80 \pm 7^{*} \dagger$ & $98 \pm 14 \dagger$ & $81 \pm 11^{*}+$ & $84 \pm 12^{*} \dagger$ & $51 \pm 6^{*} \dagger$ & $57 \pm 12^{*} \dagger$ & $76 \pm 6^{*} \dagger$ \\
\hline SIN-1 & $105 \pm 8$ & $100 \pm 11$ & $105 \pm 11$ & $93 \pm 13$ & $96 \pm 9$ & $95 \pm 12$ & $97 \pm 7$ & $94 \pm 12$ & $94 \pm 8$ \\
\hline
\end{tabular}

$C P B$, Cardiopulmonary bypass.

${ }^{*} P<.05$ compared with baseline data within the same group.

$\dagger P<.05$ compared with the control group at the same time point.

\section{Results}

\section{Reperfusion Impairment in Hemodynamic} Measurements and cTnI Levels

No significant differences in the recovery of the hemodynamic measurements (mean blood pressure, heart rate, $\mathrm{dP} /$ dT) were observed among animals in the control, L-Arg, and SIN-1 groups at any time during the experiments (Table 1). However, after 60 minutes of cardioplegia-induced cardiac arrest, recovery of $\mathrm{dP} / \mathrm{dT}$ in the L-NMMA group was significantly different from that observed in the other 3 groups $(0.51 \pm 0.06$ for the L-NMMA group and $0.92 \pm 0.04,0.95$ \pm 0.09 , and $0.97 \pm 0.07$ for the control, L-Arg, and SIN-1 groups, respectively; $P<.05$ ), and remained significantly different through the experimental process (Figure 1, A). The plasma levels of cTnI at baseline and immediately upon initiation of CPB among all 4 groups were undetectable. However, the plasma levels of $\mathrm{cTnI}$ in the L-NMMA group were significant higher than that of the other 3 groups 5 minutes after aortic crossclamps were released $(85.76 \pm 6.7$ $\mathrm{ng} / \mathrm{mL}, P<.05)$ and 4 hours after dogs were weaned from CPB (204.49 $\pm 26.4 \mathrm{ng} / \mathrm{mL}, P<0.05)$. Nevertheless, the plasma levels of cTnI of the control group at the above time points $(47.2 \pm 3.1$ and $147.5 \pm 4.6 \mathrm{ng} / \mathrm{mL}, P<.05)$ were also significant higher than those observed in the L-Arg $(14.0 \pm 2.1$ and $24.6 \pm 6.9 \mathrm{ng} / \mathrm{mL})$ and SIN-1 groups (21.2 \pm 10.5 and $52.9 \pm 7.1 \mathrm{ng} / \mathrm{mL}$; Figure $1, B$ ).

\section{Detection of Apoptosis in Myocardium by the TUNEL Method}

Cardiomyocyte nuclei with nicked DNA were present in all groups. Four sections of the left ventricle in each animal were examined to determine the percentage of apoptotic nuclei. Apoptotic cell counts were expressed as a percentage of the total number of nuclei counted. The percentage of apoptotic cardiomyocyte nuclei was significantly higher in the control $(9.8 \pm 0.6 \% / \mathrm{HPF})$ and L-NMMA $(10.3 \% \pm$ $1.3 \% / \mathrm{HPF})$ groups than in the L-Arg $(5.9 \% \pm 0.6 \% / \mathrm{HPF}, P$ $<.01)$ and SIN-1 $(3.8 \% \pm 0.9 \% / \mathrm{HPF}, P<.01)$ groups. Furthermore, the occurrence of apoptotic cardiomyocytic nuclei was significantly lower in the SIN-1 group than in the
L-Arg group $(P<.01)$. However, the difference in number of apoptotic nuclei between the control and L-NMMA groups was not statistically significant (Figure 2, B).

Detection of Caspase-3 Activation by Western Blotting Caspase-3 plays a role as a key protease of the apoptotic machinery. We examined whether global cardiac ischemia/ reperfusion actually induced caspase- 3 cleavage as a prerequisite for caspase- 3 enzymatic activity. As PARP protein is known to be a major substrate for active caspase-3 and PARP degradation (a hallmark of apoptosis), Western blot analysis for PARP protein was performed. The intact 116$\mathrm{kDa}$ PARP was degraded, as shown by the increasing quantity of 24-kDa cleavage product detected using N-terminal binding antibody (Figure 2, C). Using densitometry analyses, we found that levels of activated caspase- 3 levels were higher in the control $(4312 \pm 498)$ and L-NMMA (6053 \pm 253) groups than in the L-Arg $(3646 \pm 399, P<.05$ and $P$ $<.01$, respectively) and SIN-1 (1731 $\pm 437, P<.01$ and $P<0.01$, respectively; Figure $2, A$ ) groups.

\section{Detection of NADH:Ubiquinone Oxidoreductase Gene Up-regulation by RT-PCR}

RT-PCR of mRNA from the cardiac tissue specimens confirmed the presence and differential up-regulation of the NADH:ubiquinone oxidoreductase gene among the 4 groups. As shown in Figure 3, RT-PCR detected NADH: ubiquinone oxidoreductase gene protein mRNA up-regulation in cardiac tissue in all 4 groups. Densitometric semiquantitative analysis implied significant up-regulation in the control $(6698 \pm 256, P<.01)$ and L-NMMA $(9268 \pm 176$, $P<.01)$ groups compared with the SIN-1 group (2357 \pm 141). The mRNA up-regulation observed in the L-Arg group $(4198 \pm 312)$ was also significantly lower than that of the control $(P<.01)$ and L-NMMA $(P<.01)$ groups. However, the difference in mRNA up-regulation between the SIN-1 and L-Arg $(P<.01)$ groups and the L-NMMA and control $(P<.01)$ groups was also statistically significant.

In our study, Bcl-2 and cytochrome $c$ protein expression was significantly different in the L-Arg and SIN-1 groups 
(A) $\mathrm{dP} / \mathrm{dT}$

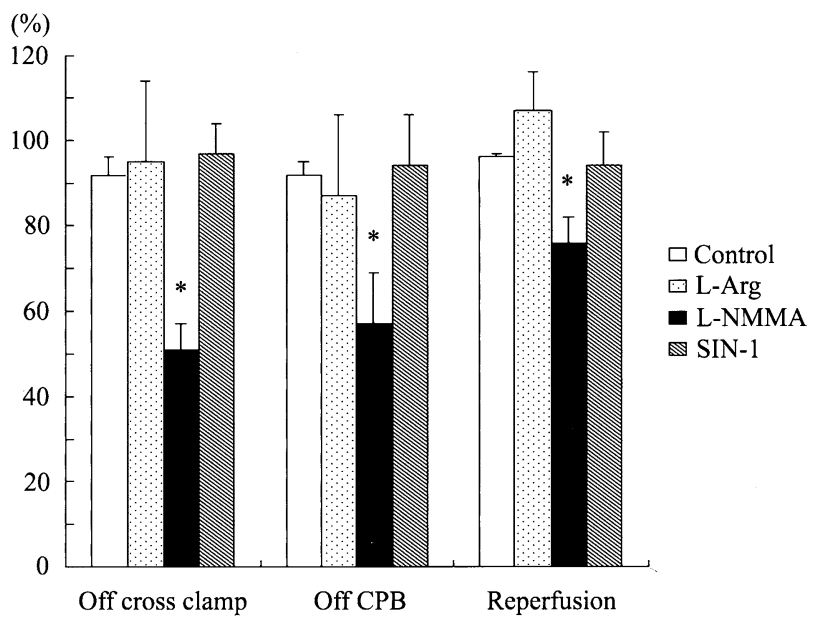

(B) cTnI level

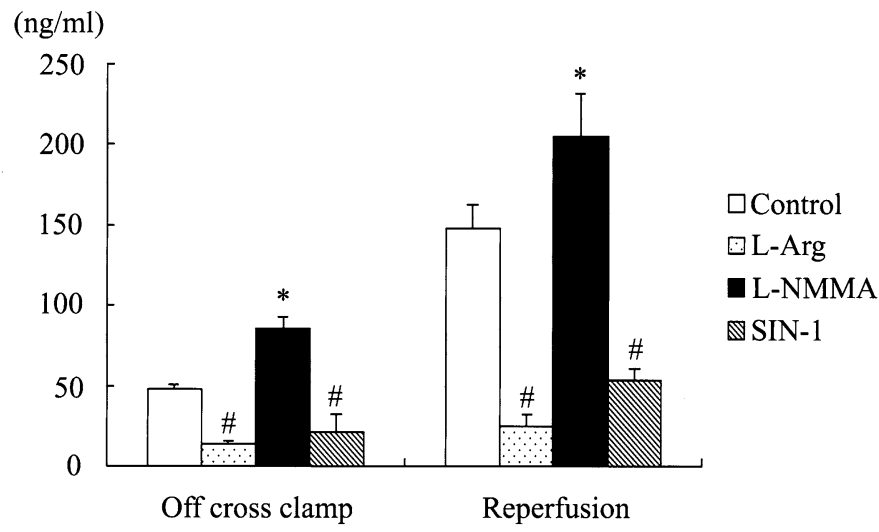

Figure 1. Relationship among various groups, release of cardiac troponin $I$, and recovery of dP/dT during reperfusion. A, Recovery of $\mathrm{dP} / \mathrm{dT} 5$ minutes after releasing the aortic crossclamp (off crossclamp), 5 minutes after dogs were weaned off CPB (off CPB), and 4 hours after CPB termination (reperfusion) in the 4 groups. B, Plasma levels of cTnl collected at different time points in all 4 groups undergoing global cardiac ischemia-reperfusion using CPB. Data are presented as the mean \pm standard error of the mean. ${ }^{*} P<.05$ versus control group. \#P<.05 versus both control and L-NMMA groups.

compared with the control and L-NMMA groups $(P<.05$, Figure $4, A$ ). Densitometry analyses showed that the levels (expressed in optical density units) of Bcl-2 were significantly higher in the SIN-1 $(3060 \pm 247)$ and L-Arg $(3145 \pm$ 158) groups than in the control $(1490 \pm 163, P<.05$ for both comparisons) and L-NMMA (490 $\pm 79, P<.05$ for both comparisons) groups. On the other hand, the SIN-1 (10772 $\pm 2046, P<.05$ for both comparisons) and L-Arg (12155 $\pm 1938, P<.05$ for both comparisons) groups significantly decreased the expression of cytochrome $c$ than the control (15074 \pm 1059$)$ and L-NMMA (16982 \pm 1588 ; Figure $4, B$ ) groups. However, the expression of both proteins was not significantly different between the SIN-1 and L-Arg groups and the control and L-NMMA groups.

\section{Discussion}

In the development of cardioplegic cardioprotection during cardiac surgery, many different formulations of cardioplegic solutions have been investigated and applied in clinical use. Using various methods of cardioprotection, cardiomyocytic necrosis can be minimized in modern cardiac surgery. However, cardiomyocytic apoptosis occurs when ischemic insult is delivered in doses milder than that required for necrosis. ${ }^{15}$ Despite improvements made in every method, ischemia-reperfusion injury of cardiomyocytes occurs during aortic crossclamping, even with continuous tepid blood cardioplegic solution cardioprotection. Apoptosis may be involved in the progression of dilated cardiomyopathy, in that loss of cardiomyocytes promotes myocardial 


\section{(A)} Cleaved Caspase-31

(B)

(C)

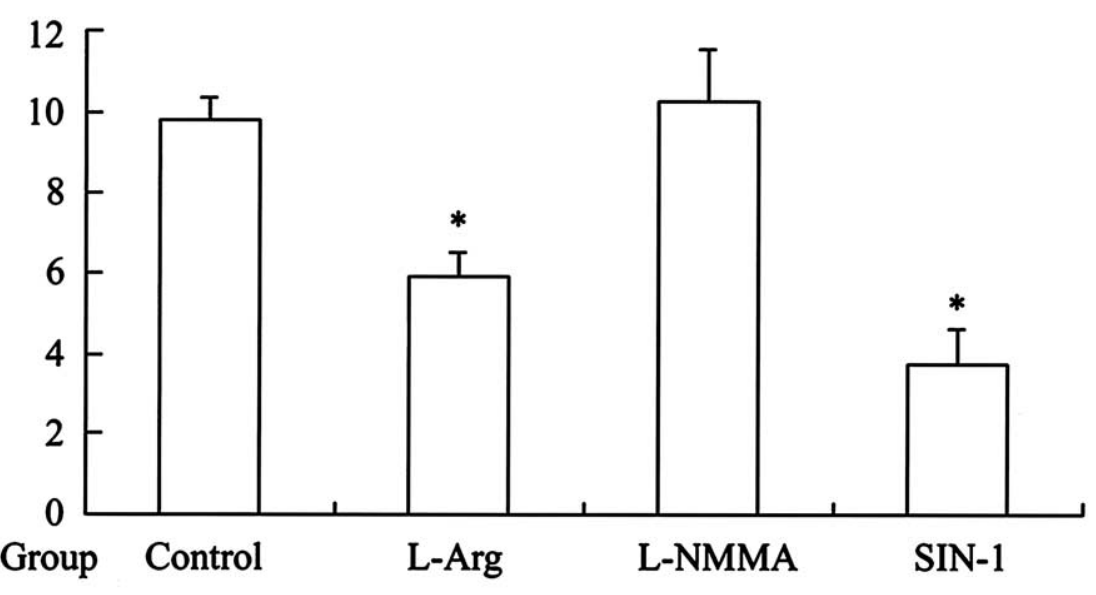

\section{Cleaved PARP}

Figure 2. Effect of NO-enriched cardioplegia on cardiopulmonary bypass (CPB)-induced cardiomyocytic apoptosis. $B$, The number of apoptotic nuclei in different groups stained with the TUNEL (terminal deoxynucleotidyl transferase-mediated dUTP-biotin nick end labeling) method. C, Western blot analysis of caspase-3 (A) and poly-(ADP-ribose) polymerase (PARP) in different groups was performed. Using densitometry analyses, the activated caspase-3 of the control and L-NMMA groups were significantly higher than that of the other 2 groups. ${ }^{*} P<.05$ versus control and $<.01$ versus L-NMMA group.
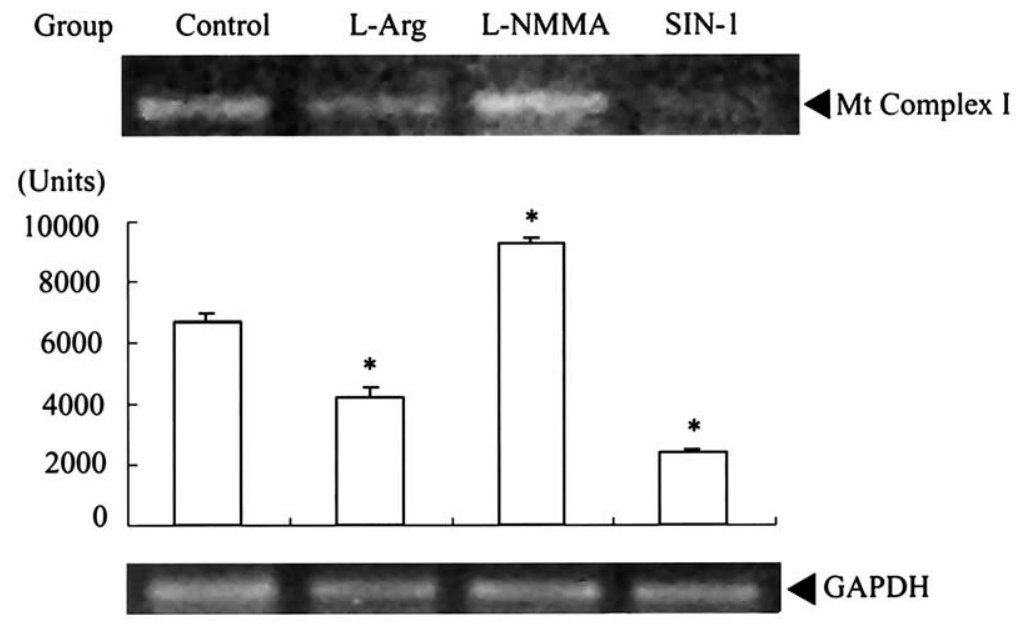

Figure 3. Reverse-transcription polymerase chain reaction analysis showing up-regulation of part of NADH: ubiquinone oxidoreductase gene in cardiac tissue in the different groups. Glyceraldehyde-3-phosphate dehydrogenase (GAPDH) served as the loading control. The PCR products of GAPDH and NADH:ubiquinone oxidoreductase gene were designed to be 200 bp. ${ }^{*} P<.01$ versus control.

dysfunction, resulting in heart failure. Furthermore, apoptosis was proven to be evident early after cardiac surgery and correlates with declining cardiac contractility. ${ }^{5}$
Our previous studies revealed that different cardioplegic solutions have various effects on the occurrence of coronary endothelial damage and cardiomyocytic apoptosis ${ }^{6}$ and sug- 
(A) Bcl-2 Group Control L-Arg L-NMMA SIN-1

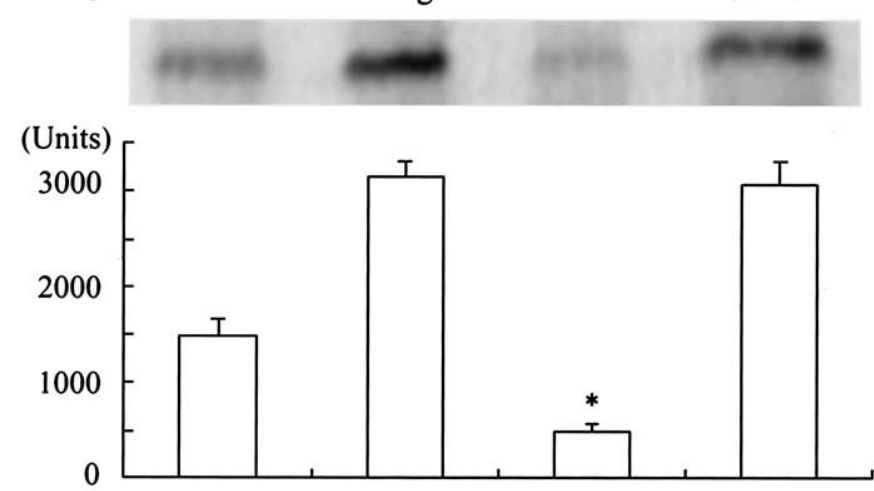

(B) Cytochrome c

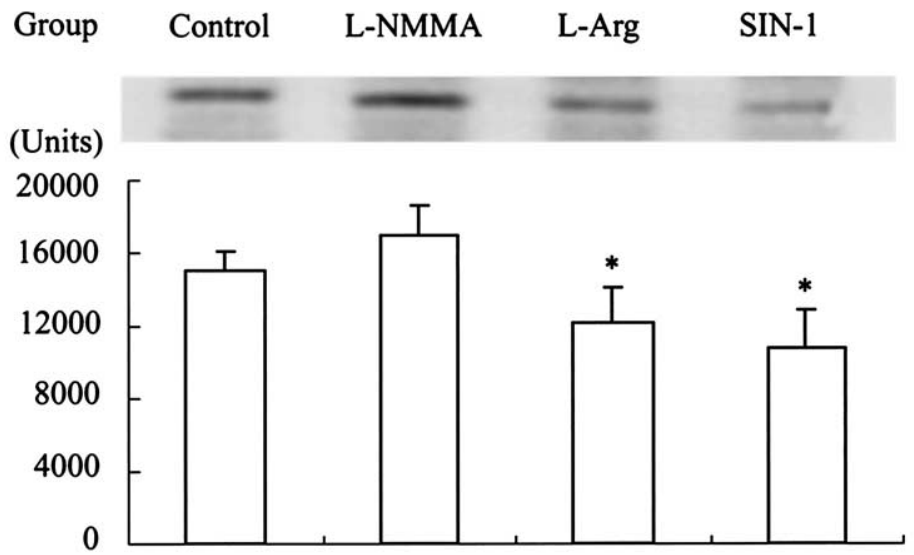

Figure 4. Western blot analysis of Bcl-2 and cytochrome $c$ in different groups: $(A) B c l-2\left({ }^{*} P<.05\right.$ versus control and L-NMMA groups), (B) cytochrome $c\left(^{*} P<.05\right.$ versus control and L-NMMA groups).

gested the possible role of mitochondrial NADH:ubiquinone oxidoreductase in this process. ${ }^{7}$ The anatomic impairment of coronary endothelium during cardioplegic cardiac arrest is associated with the deterioration its vasorelaxation function, ${ }^{16,17}$ which is mediated largely via NO. NO can protect cells from apoptosis induced by many different types of stimuli such as tumor necrosis factor- $\alpha$, oxidative stress, and serum or glucose deprivation. ${ }^{18}$ The biochemical mechanism underlying NO-mediated antiapoptotic effects involves multiple signal pathways, including the mitochondria-dependent pathway. NO can rapidly inactivate mitochondrial complex I, ${ }^{19}$ elevate mRNA and protein levels of Bcl-2 expression, and prevent apoptotic cell death. ${ }^{20} \mathrm{How}-$ ever, these effects could be abolished with cardioplegiainduced cardiac ischemia-reperfusion injury under CPB, which had similar results as inhibition of NO synthase. ${ }^{19}$ Mitochondrial complex I, which produces superoxide, has been reported to be associated with an increased hydrogen peroxide production ${ }^{21}$ and cardiomyocytic damage ${ }^{22}$ after ischemia-reperfusion injury. In our previous study, ${ }^{7}$ we demonstrated that with better cardiomyocytic preservation, the up-regulation of part of the mitochondrial complex I and cardiomyocytic apoptosis was lessened. Thus, we hypothesized that NO-enriched cardioplegic solution could decrease the occurrence of cardiomyocytic apoptosis by activation of $\mathrm{Bcl}-2$ protein, prevent the up-regulation of mitochondrial NADH:ubiquinone oxidoreductase, diminish the release of cytochrome $c$ from mitochondria, and ameliorate the activation of caspase cascade.

The impact of ischemia-reperfusion insult on the cardiomyocytic mitochondrial respiratory chain has been studied previously. Kotamraju and colleagues ${ }^{22}$ suggested that mitochondrial electron transfer complex I might represent the primary site of hydrogen peroxide formation and succeeding cardiomyocytic apoptosis. Hardy and coworkers ${ }^{23}$ reported that the activity of complex I decreased following reperfusion, which resulted in an increase in intracellular $\mathrm{Ca}^{2+}$. They also demonstrated that following a hypoxic episode, the increased activity of mitochondrial complex I would impair myocardial recovery. In our previous study, ${ }^{7}$ 
we indicated that during global cardiac arrest under CPB, cardiomyocytic mitochondrial up-regulation correlated with the occurrence of cardiomyocytic apoptosis, which implied that with better myocardial protection, ischemia-reperfusion-induced mitochondrial complex I mRNA up-regulation would be reduced. In this study, we used an NOenriched cardioplegic solution to supplement the deteriorated endothelial NO production. Our results suggest that prevention of the mitochondrial complex I up-regulation might be 1 possible mechanism of how NO-enriched cardioplegic solution ameliorated ischemia-reperfusion injury to the cardiomyocytes.

The activation of caspases by proapoptotic stimuli occurs via several interdependent pathways. Whether a cell undergoes apoptosis appears to be due to a shift in the balance between anti- and proapoptotic factors in favor of the "pro" factors. Kim and colleagues ${ }^{24}$ reported that physiologically relevant levels of NO can contribute to this balance by modulating the level of caspase-3-like protease activity through both direct and indirect mechanisms. Exogenous NO-donating agents clearly can elicit beneficial actions relevant to cardiovascular disorders. ${ }^{25} \mathrm{NO}$ has been postulated to inhibit apoptosis by a variety of mechanisms including inhibition of transcription factor-dependent Fas ligand expression, ${ }^{26}$ cyclic guanosine monophosphatedependent signaling cascades ${ }^{27}$ and direct nitrosylation of caspases-3 and $-8 .{ }^{24}$ An important type of apoptosis, which is mediated via mitochondria, is the direct cytochrome $c$-dependent activation of caspase- $3 .{ }^{28} \mathrm{NO}$ could also maintain the mitochondrial membrane potential during stimuli, regulate the $\mathrm{Bcl}-2$ proteins, decrease cytochrome $c$ release, and prevent cell apoptosis. ${ }^{29}$ Matsumoto and colleagues ${ }^{30}$ demonstrated the interaction between NO synthase and procaspase- 3 could be modified with L-arginine or L-NMMA via the mitochondrial pathway. ${ }^{30}$ Damage to the vascular endothelium during global cardiac arrest using cardioplegic solution under CPB has been documented, ${ }^{17}$ and the impairment of endothelium results in decreasing production of NO. With a disturbance in the NO production balance, the NO-mediated antiapoptotic pathway would be inhibited. In this study, we demonstrated that restoration of the physiologic NO production balance could resume the NO-mediated antiapoptotic pathway, increasing the expression of Bcl-2 proteins and ameliorating cytochrome $c$ release, thus protecting the cardiomyocytes from apoptosis. On the other hand, inhibition of NO synthase would diminish the production of NO and aggravate apoptosis after cardioplegiainduced cardiac global ischemia-reperfusion injury under CPB.

In the present study, we demonstrated that: (1) cardioplegic solutions supplemented with NO donor (SIN-1) or NO synthase substrate (L-arginine) could elevate the expression of Bcl-2, which inhibits the mitochondrial pathway of apo- ptosis; (2) cardioplegic solutions supplemented with NO donor (SIN-1) or NO synthase substrate (L-arginine) could decrease the up-regulation of mitochondrial NADH:ubiquinone oxidoreductase mRNA; (3) cardioplegic solutions supplemented with NO donor (SIN-1) or NO synthase substrate (L-arginine) could inhibit apoptosis downstream of cytochrome $c$ release; (4) cardioplegic solutions supplemented with NO donor (SIN-1) or NO synthase substrate (L-arginine) could inhibit caspase 3 activation in cells; and (5) cardioplegic solutions supplemented with NO synthase inhibitor (L-NMMA) could increase the up-regulation of mitochondrial NADH:ubiquinone oxidoreductase mRNA, decrease the expression of $\mathrm{Bcl}-2$, elevate the expression of caspase-3, and aggravate cardiomyocytic apoptosis. These data indicate that NO-enriched cardioplegic solutions may inhibit the mitochondrial pathway of apoptosis by prevention of the NADH:ubiquinone oxidoreductase up-regulation. These findings have implications for the mechanisms of cardiomyocytic apoptosis that arise during global cardiac arrest due to the use of cardioplegic solution during CPB and also suggest prevention strategies for postoperative myocardial failure.

\section{References}

1. Ku DD. Coronary vascular reactivity after acute myocardial ischemia. Science. 1982;218:576-8.

2. VanBenthuysen KM, McMurtry IF, Horwitz LD. Reperfusion after acute coronary occlusion in dogs impairs endothelium-dependent relaxation to acetylcholine and augments contractile reactivity in vitro. J Clin Invest. 1987;79:265-74.

3. Tsao PS, Aoki N, Lefer DJ, Johnson G 3rd, Lefer AM. Time course of endothelial dysfunction and myocardial injury during myocardial ischemia and reperfusion in the cat. Circulation. 1990;82:1402-12.

4. Nakanishi K, Zhao ZQ, Vinten-Johansen J, Hudspeth DA, McGee DS, Hammon JW Jr. Blood cardioplegia enhanced with nitric oxide donor SPM-5185 counteracts postischemic endothelial and ventricular dysfunction. J Thorac Cardiovasc Surg. 1995;109:1146-54.

5. Schmitt JP, Schröder J, Schunkert H, Birnbaum DE, Aebert H. Role of apoptosis in myocardial stunning after open heart surgery. Ann Thorac Surg. 2002;73:1229-35.

6. Yeh CH, Wang YC, Wu YC, Chu JJ, Lin PJ. Continuous tepid blood cardioplegia can preserve coronary endothelium and ameliorate the occurrence of cardiomyocytic apoptosis. Chest. 2003;123:1647-54.

7. Yeh $\mathrm{CH}, \mathrm{Wu} \mathrm{YC}$, Wang YC, Chu JJ, Lin PJ. Differential-display polymerase chain reaction identifies NADH:ubiquinone oxidoreductase as an ischemia/reperfusion-regulated gene in cardiomyocytes. Chest. 2004;125:228-35.

8. Brooks SP, Lampi BJ, Sarwar G, Botting HG. A comparison of methods for determining total body protein. Anal Biochem. 1995;226: 26-30.

9. Chomczynski P, Sacchi N. Single-step method of RNA isolation by acid guanidinium thiocyanate-phenol-chloroform extraction. Anal Biochem. 1987;162:156-9.

10. Ellis RE, Yuan J, Horvitz R. Mechanisms and functions of cell death. Annu Rev Cell Biol. 1991;7:663-98.

11. Cheng W, Kajstura J, Nitahara JA, Li B, Reiss K, Liu Y, et al. Programmed myocyte cell death affects the viable myocardium after infarction in rats. Exp Cell Res. 1996;226:316-27.

12. Kajstura J, Mansukhani M, Cheng W, Reiss K, Krajewski S, Reed JC, et al. Programmed cell death and expression of the protooncogene bcl-2 in myocytes during postnatal maturation of the heart. Exp Cell Res. 1995;219:110-21. 
13. Olivetti G, Abbi R, Quaini F, Kajstura J, Cheng W, Nitahara JA, et al. Apoptosis in the failing human heart. N Engl J Med. 1997;336:113141.

14. Yang J, Liu X, Bhalla K, Kim CN, Ibrado AM, Cai J, et al. Prevention of apoptosis by $\mathrm{Bcl}-2$ : release of cytochrome $\mathrm{c}$ from mitochondria blocked. Science. 1997;275:1129-32.

15. Narula J, Dawson MS, Singh BK, Amanullah A, Acio ER, Chaudhry FA, et al. Noninvasive characterization of stunned, hibernating, remodeled and nonviable myocardium in ischemic cardiomyopathy. J Am Coll Cardiol. 2000;36:1913-9.

16. Pearson PJ, Lin PJ, Schaff HV. Global ischemia and reperfusion impair endothelium-dependent relaxations to aggregating platelets in the canine coronary artery. A possible cause of vasospasm after cardiopulmonary bypass. J Thorac Cardiovasc Surg. 1992;103:114754.

17. Cooper WA, Duarte IG, Thourani VH, Nakamura M, Wang NP, Brown WM 3rd, et al. Hypothermic circulatory arrest causes multisystem vascular endothelial dysfunction and apoptosis. Ann Thorac Surg. 2000;69:696-702.

18. Chung HT, Pae HO, Choi BM, Billiar TR, Kim YM. Nitric oxide as a bioregulator of apoptosis. Biochem Biophys Res Commun. 2001;282: 1075-9.

19. Borutaite V, Budriunaite A, Brown GC. Reversal of nitric oxide-, peroxynitrite- and S-nitrosothiol-induced inhibition of mitochondrial respiration or complex I activity by light and thiols. Biochim Biophys Acta. 2000;1459:405-12.

20. Genaro AM, Hortelano S, Alvarez A, Martinez C, Bosca L. Splenic B lymphocyte programmed cell death is prevented by nitric oxide release through mechanisms involving sustained Bcl-2 levels. J Clin Invest. 1995;95:1884-90.

21. Turrens JF, Beconi M, Barilla J, Chavez UB, McCord JM. Mitochon- drial generation of oxygen radicals during reoxygenation of ischemic tissues. Free Radic Res Commun. 1991;12-13:681-9.

22. Kotamraju S, Konorev EA, Joseph J, Kalyanaraman B. Doxorubicininduced apoptosis in endothelial cells and cardiomyocytes is ameliorated by nitrone spin traps and ebselen. Role of reactive oxygen and nitrogen species. J Biol Chem. 2000;275:33585-92.

23. Hardy L, Clark JB, Darley-Usmar VM, Smith DR, Stone D. Reoxygenation-dependent decrease in mitochondrial NADH: CoQ reductase (complex I) activity in the hypoxic/reoxygenated rat heart. Biochem J. 1991;274:133-7.

24. Kim YM, Talanian RV, Billiar TR. Nitric oxide inhibits apoptosis by preventing increases in caspase-3-like activity via two distinct mechanisms. J Biol Chem. 1997;272:31138-48.

25. Ignarro LJ, Napoli C, Loscalzo J. Nitric oxide donors and cardiovascular agents modulating the bioactivity of nitric oxide: an overview. Circ Res. 2002;90:21-8.

26. Mannick JB, Miao XQ, Stamler JS. Nitric oxide inhibits Fas-induced apoptosis. J Biol Chem. 1997;272:24125-8.

27. Kim YM, Chung HT, Kim SS, Han JA, Yoo YM, Kim KM, et al. Nitric oxide protects PC12 cells from serum deprivation-induced apoptosis by cGMP-dependent inhibition of caspase signaling. J Neurosci. 1999;19:6740-7.

28. Earnshaw WC, Martins LM, Kaufmann SH. Mammalian caspases: structure, activation, substrates, and functions during apoptosis. Annu Rev Biochem. 1999;68:383-424.

29. Boyd CS, Cadenas E. Nitric oxide and cell signaling pathways in mitochondrial-dependent apoptosis. Biol Chem. 2002;383:411-23.

30. Matsumoto A, Comatas KE, Liu L, Stamler JS. Screening for nitric oxide-dependent protein-protein interactions. Science. 2003;301:65761

\section{Online-www.aats.org}

Now you can get The Journal of Thoracic and Cardiovascular Surgery online. The Journal online brings you faster delivery time, easy searching of current and back issues, links to PubMed, AATS, WTSA, and other important sites, and more. Visit the Journal online today.

\section{Receive tables of contents by e-mail}

To receive the tables of contents by e-mail, sign up through our Web site at http://www.mosby.com/jtcvs

Choose E-mail Notification

Simply type your e-mail address in the box and click the Subscribe button. Alternatively, you may send an e-mail message to majordomo@mosby.com. Leave the subject line blank and type the following as the body of your message: subscribe jtcvs_toc

You will receive an e-mail to confirm that you have been added to the mailing list.

Note that TOC e-mails will be sent out when a new issue is posted to the Web site. 